\title{
Unsafe abortion: the silent scourge
}

\author{
Sharadha Mallaiyan* \\ Department of Obstetrics and Gynecology, Thanjavur Medical College, Thanjavur, Tamil Nadu, India
}

Received: 21 May 2019

Accepted: 09 July 2019

\section{*Correspondence:}

Dr. Sharadha Mallaiyan,

E-mail: drsharadha@gmail.com

Copyright: (C) the author(s), publisher and licensee Medip Academy. This is an open-access article distributed under the terms of the Creative Commons Attribution Non-Commercial License, which permits unrestricted non-commercial use, distribution, and reproduction in any medium, provided the original work is properly cited.

\section{ABSTRACT}

Background: Unsafe abortions continue to cause maternal morbidity and mortality in developing countries. The practice of unsafe abortions by quacks needs to be checked. Our study aims to emphasize upon the unmet needs of medical termination pregnancies (MTP) services in rural India and to recognize the complications due to it and the efficient management of such cases at tertiary care center.

Methods: A two years retrospective study of septic abortions from December 2009 to November 2011.

Results: Among 1080 abortions reported, 44 were septic-4.07\%. More commonly in the age group of $>20$ years (81.9\%). $77.3 \%$ of them were multiparous and $22.7 \%$ were nulligravidae, with an increased incidence of unmarried nulliparous pregnancies. Greater numbers occurred during 1st trimester (77.2\% versus $22.7 \%$ ), with $54.5 \%$-grade I, $29.5 \%$-grade II, $15.9 \%$ grade III in severity. Majority of cases were due to evacuation by quacks (72.7\%). Among the 44 cases, emergency laparotomy was done for 5 cases of grade III severity. The mortality rates due to septic abortion were $6.25 \%$ (3) among the total of 48 maternal deaths.

Conclusions: Septic abortion is totally preventable. Majority of uneducated rural women are not aware of MTP services. The reproductive and child health $(\mathrm{RCH})$ services should effectively reach the underprivileged population like slum dwellers and migrants.

Keywords: Quacks, MTP services, MTP act, Rural India, Septic abortion, Unwanted pregnancies, Unsafe abortion

\section{INTRODUCTION}

The existence of unsafe abortions in rural India even at this era highlights the unawareness of the various contraceptive methods available as provided by the family welfare department, Government of India, to avoid unwanted pregnancies, especially the teenage and unwed pregnancies. ${ }^{1}$

The magnitude of the problem as it is existing in the rural India needs to be projected and highlighted, since performing an Unsafe abortion can cost a woman's life. The seriousness of the methods used by the village quacks to induce miscarriage in unwanted pregnancies is yet to be recognized by the society as it can lead to serious maternal morbidity and mortality.
My study aims to emphasize upon the unmet needs of MTP services in rural India and to recognize the complications due to it and the efficient management of such cases at tertiary care center.

\section{Worldwide incidences}

The World Health Organization (WHO) estimated that for the time period between 2010 to 2014, there were 55.7 million abortions worldwide each year. Out of these abortions, approximately $54 \%$ were safe, $31 \%$ were less safe, and $14 \%$ were least safe. That means that 25 million (45\%) abortions each year between 2010 and 2014 were unsafe, with 24 million (97\%) of these in developing countries. $^{2}$ According to WHO statistics, the risk rate for unsafe abortion is $1 / 270$; according to other sources, 
unsafe abortion is responsible for at least $8 \%$ of maternal deaths. $^{3,4}$ Worldwide, $48 \%$ of all induced abortions are unsafe.

The aim of the study was to determine the incidence, clinical features, management, complications, morbidity and mortality of the septic abortion and to highlight the magnitude of the problem of unsafe abortion in rural India.

The study was performed in Thanjavur, an important agricultural center located in the Cauvery Delta in south India and is known as the "Rice bowl of Tamil Nadu".

\section{METHODS}

The study was conducted at the Raja Mirasudar Hospital - Thanjavur Medical College, a tertiary care institute at Thanjavur, Tamil Nadu, India.

The study design was a two years retrospective study of septic abortions from December 2009 to November 2011. The study population included all cases of abortions as defined by World Health Organization (WHO) as pregnancy termination prior to 20 weeks of gestation or a fetus born weighing less than $500 \mathrm{gm} .^{5}$

Amongst the total abortions of 1080 during the 2-year study period, 1036 cases were diagnosed as threatened miscarriage, complete and incomplete miscarriage, missed miscarriage were omitted from the study and was managed accordingly.

44 cases which satisfied the criteria of septic abortions were selected. The selection criteria being, all suspected cases of abortions either spontaneous/induced presenting with signs of sepsis like - Fever > 100.4, offensive/purulent vaginal discharge, lower abdominal pain, uterine tenderness, and those cases with $\mathrm{H} / \mathrm{O}$ uterine evacuation done by quacks. Hence sample size for our study was decided to be 44 .

All the 44 cases were assigned a grade as per the severity of the infection into III grades. Grade I - Infection localized to the uterus, Grade II - infection spreading beyond the uterus to the parametrium, tubes and ovaries or pelvic peritoneum, Grade III - Patients having generalized peritonitis and/or endotoxic shock or jaundice or acute renal failure.

Data were collected from labor ward casualty referral register - which included all referrals to our hospital from primary health centre, community health center and private hospitals, inpatient case sheets, operative notes register and maternal mortality register.

\section{Statistical analysis}

For this retrospective study, the categorical findings were expressed in the form of frequency, percentage and presented by tables and graphs. The Tables and graphs were presented by using Microsoft Excel.

\section{RESULTS}

The total number of abortions during the study period was 1080. They included threatened miscarriages, incomplete and complete miscarriages, missed miscarriages and septic abortions. There were 44 septic abortions $(4.07 \%$ ) in our study (Table 1$)$.

Among the 44 cases, $8(18.1 \%)$ woman were in the age group of <20years, $14(31.8 \%)$ were in the age group of 20-25years, $12(27.7 \%)$ were in the age group of 26-30 years. $9(20.4 \%)$ were in the age group of $>31-40$ years, $1(2.27 \%)$ was in the age group of $>40$ years (Table 2 ).

Table 1: Incidence of septic abortions.

\begin{tabular}{|lll|}
\hline Type & Number & Percentage (\%) \\
\hline Total abortions & 1080 & 95.93 \\
\hline Septic abortions & 44 & 4.07 \\
\hline
\end{tabular}

Table 2: Incidence with respect to age.

\begin{tabular}{|lll|}
\hline Age & Frequency & Percentage $(\%)$ \\
\hline$<20$ years & 8 & 18.10 \\
\hline 20-25 years & 14 & 31.80 \\
\hline 26-30 years & 12 & 27.27 \\
\hline 31-40 years & 9 & 20.40 \\
\hline$>40$ years & 1 & 2.27 \\
\hline
\end{tabular}

There were $10(22.7 \%)$ nulligravidas, with an increased incidence of unmarried nulliparous pregnancies.34 (77.2\%) multigravidas of whom 35\% (12/34) were grand multiparas (parity 4 or more) (Table 3 ). Greater numbers occurred during 1 st trimester $34(77.2 \%)$ versus 10 $(22.7 \%)$ in the $2^{\text {nd }}$ trimester.

Table 3. Incidence with respect to parity

\begin{tabular}{|lll|}
\hline Parity & Frequency & Percentage (\%) \\
\hline Multigravida & 34 & 77.20 \\
\hline Nulligravida & 10 & 22.70 \\
\hline
\end{tabular}

Table 4: Grading of infection.

\begin{tabular}{|lll|}
\hline Grade & Frequency & Percentage (\%) \\
\hline Grade I & 24 & 54.50 \\
\hline Grade II & 13 & 29.50 \\
\hline Grade III & 7 & 15.90 \\
\hline
\end{tabular}

Table 5: Procedure performed by.

\begin{tabular}{|lll|}
\hline Type & Frequency & Percentage (\%) \\
\hline Spontaneous & 5 & 11.36 \\
\hline Quacks & 32 & 72.73 \\
\hline Trained personnel & 7 & 15.91 \\
\hline
\end{tabular}




\section{Grading of infection ${ }^{6}$}

In our study, 24 cases (54.5\%) had grade I infection, where the infection was localized to the uterus (Table 4). While 13 cases $(29.5 \%)$ had infection spreading beyond the uterus, to the parametrium, tubes and ovaries or pelvic peritoneum which was categorized as grade either were 7 cases $(15.9 \%)$ with generalized peritonitis and/or endotoxic shock and/or multiorgan failure and was categorized as grade III infection.

Spontaneous abortions becoming septic contributed 5 cases $(11.36 \%)$. Majority of the induced abortions were by quacks-32 $(72.7 \%)$ and there were 7 cases $(15.9 \%)$ performed by trained personnel (Table 5).

\section{The cases were managed as follows at our institute}

There were 32 cases $(72.7 \%)$ in various grades of infection with retained products of conception which required dilatation and curettage and removal of the septic products of conception under intravenous antibiotic coverage. 7 cases $(15.9 \%)$ presented with pelvis abscess which required ultrasound guided Colpotomy and drainage of the pus under intravenous antibiotic coverage. Exploratory laparotomy was done in 5 cases $(11.36 \%)$ for grade III sepsis with suspected uterine and bowel perforation (Table 6). The age distribution of laparotomy cases was, 1 girl was <20years, 1 woman was 27 years $(25$ to 30 years.), remaining 3 women were between 31 to 35 years. (Table 7). There were 4 multigravida and 1 unmarried primigravida among the laparotomy cases.

Table 6: Management.

\begin{tabular}{|lll|}
\hline Procedure & Frequency & Percentage (\%) \\
\hline $\begin{array}{l}\text { Dilatation and } \\
\text { evacuation }\end{array}$ & 32 & 72.73 \\
\hline Colpotomy & 7 & 15.91 \\
\hline Laparotomy & 5 & 11.36 \\
\hline
\end{tabular}

Table 7: Age distribution of laparotomy cases.

\begin{tabular}{|lll|}
\hline Age & Frequency & Percentage $(\%)$ \\
\hline$<20$ years & 1 & 20 \\
\hline $25-30$ years & 1 & 20 \\
\hline $31-35$ years & 3 & 60 \\
\hline
\end{tabular}

Of them, total hysterectomy and bilateral salphingooopherectomy was carried out in the 19years. old unmarried nulliparous girl, who presented with grade IIIII infection and severe anemia. She gave history of surgical MTP for unwanted pregnancy by a dai (untrained midwife), with an instrument followed by insertion of a medicine through vagina 10 days before.

Laparotomy was performed for suspected uterine perforation with bowel injury. Per-operatively: Uterus, both tubes and ovaries were found to be gangrenous, thrombosed uterine vessels were found on both sides and a small $1 \times 0.5 \mathrm{~cm}$ sealed perforation was present on the posterior wall of the uterus. Total abdominal hysterectomy and bilateral salphingo-oopherectomy was done under higher intravenous antibiotic coverage. She recovered well during the postoperative period.

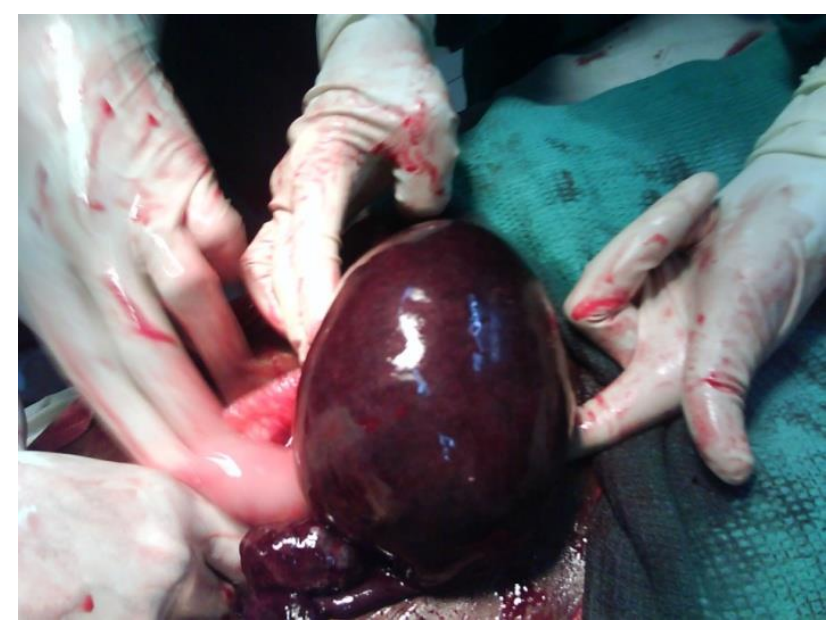

Figure 1: On laparotomy- uterus is found to be gangrenous.

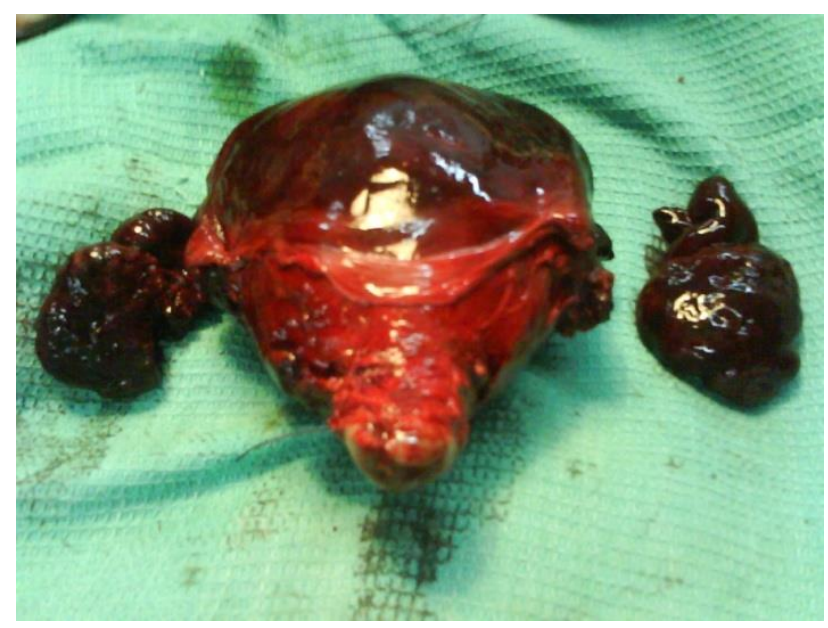

Figure 2: TAH-BSO specimen showing bilateral gangrenous adnexa and uterus.

(Figure 1 - On laparotomy- uterus is found to be gangrenous, Figure 2 - Total abdominal hysterectomy and bilateral salphingo-oopherectomy specimen showing bilateral gangrenous adnexa and uterus and Figure 3 TAH-BSO specimen showing cut surface of the gangrenous uterus with evidence of sealed perforation on the posterior wall).

Another case of Grade III infection, for whom exploratory laparotomy was performed, was a 32-year old multiparous woman admitted with complaints of diffuse abdominal pain and low-grade fever for 1 week. She presented history of instrumental evacuation performed 3 weeks before the fever, for 8 weeks pregnancy by a village quack. Under clinical suspicion of peritonitis 
secondary to septic abortion with uterine perforation and suspected bowel injury, she was taken up for Emergency Laparotomy under higher antibiotic coverage. A sealed perforation of $1 \times 1 \mathrm{~cm}$ was found at the anterior wall of the uterus. Small bowel starting from duodeno-jejunal flexure to about $50 \mathrm{~cm}$ from ileocecal junction was gangrenous, with multiple perforations. Hence small bowel resection and and anastomosis was done. Despite of the efforts, she died on the $2^{\text {nd }}$ POD due to septicemia with multiorgan failure.

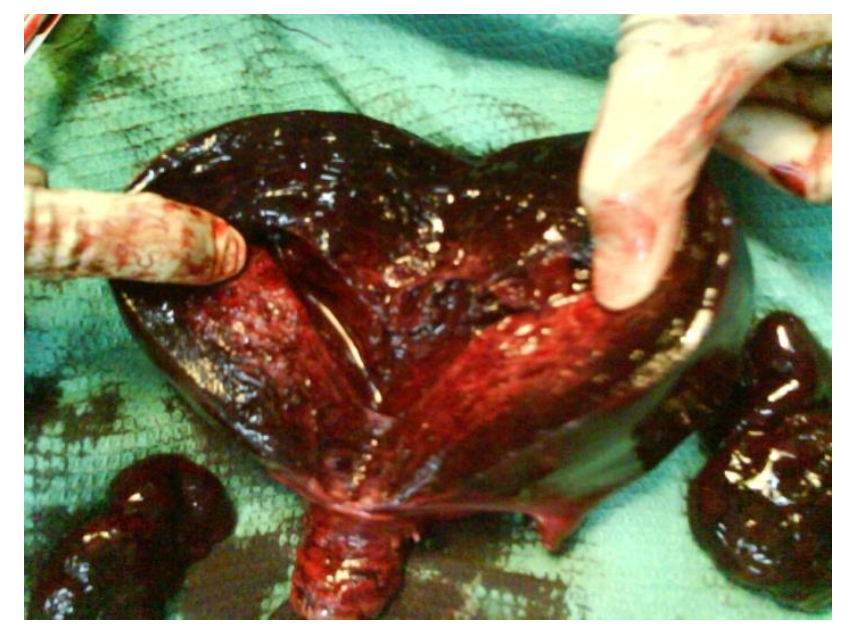

Figure 3: TAH-BSO specimen showing cut surface of the gangrenous uterus with evidence of sealed perforation on the posterior wall.

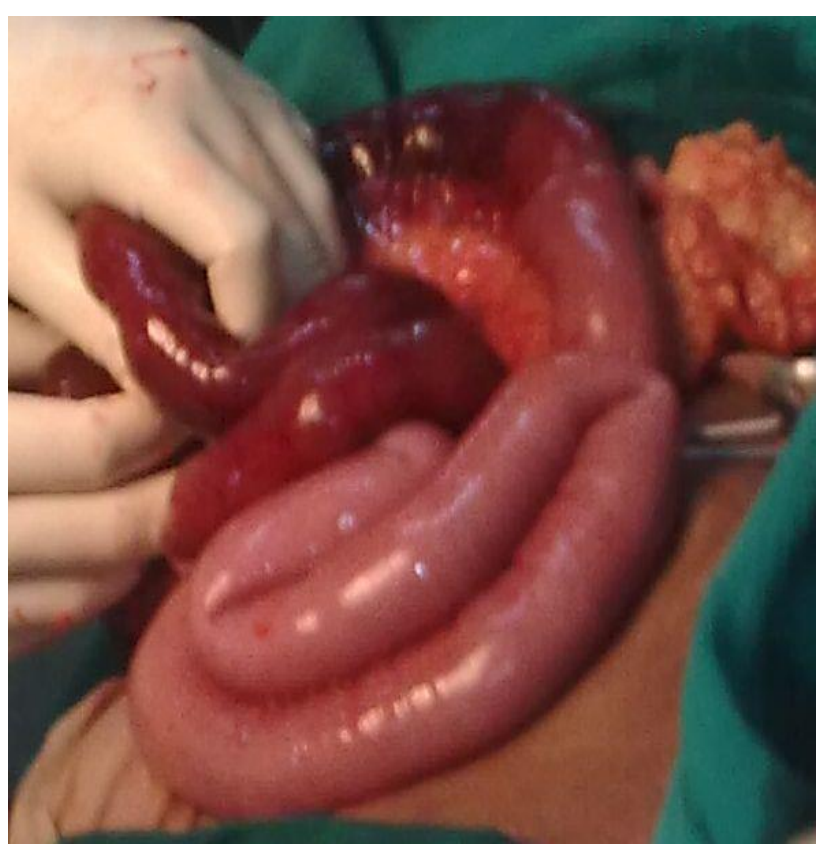

Figure 4: Exploratory laparotomy revealed multiple small intestinal perforation and gangrenous bowel from duodeno-jejunal flexure to about $50 \mathrm{~cm}$ from ileocecal junction.

(Figure 4, exploratory laparotomy revealed multiple small intestinal perforation and gangrenous bowel from duodeno-jejunal flexure to about $50 \mathrm{~cm}$ from ileocecal junction. Figure 5 - due to violent curettage, the uterus and intestines were perforated to cause ischemic injury of the small bowel and gangrene of the intestine).

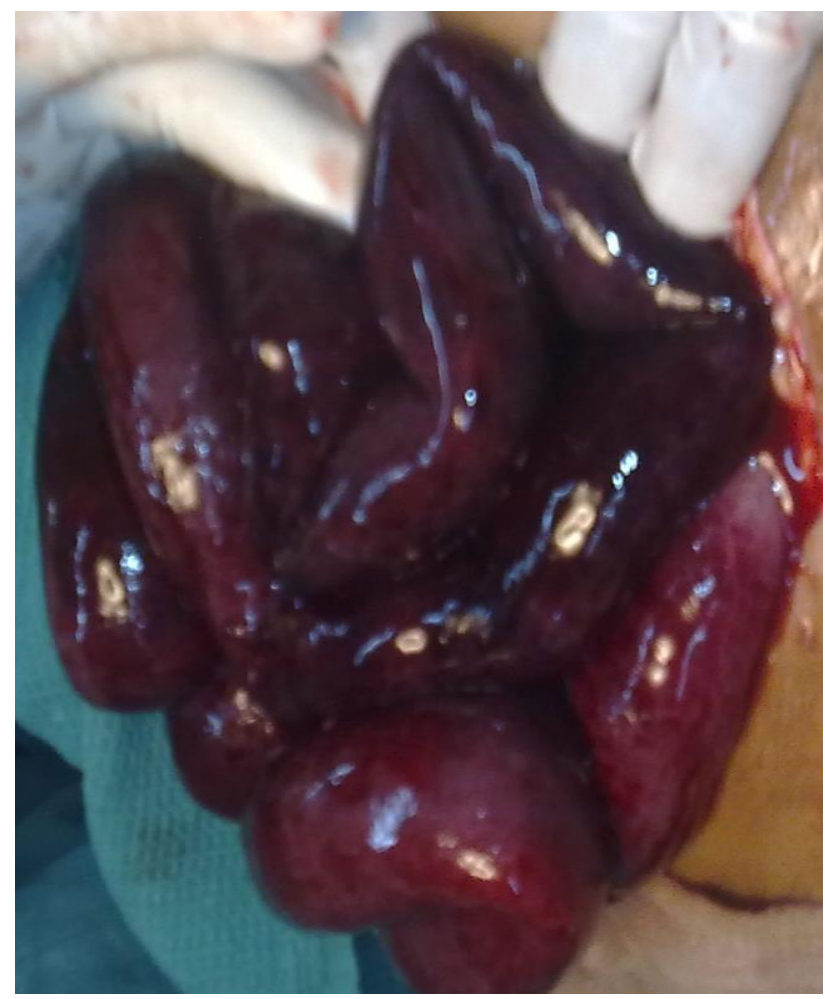

Figure 5: Gangrenous small bowel.

Table 8: Procedure at laparotomy.

\begin{tabular}{|lll|}
\hline Procedure & Frequency & Percentage (\%) \\
\hline Hysterectomy & 1 & 20.00 \\
\hline Rent repair & 2 & 40.00 \\
\hline Bowel repair & 2 & 40.00 \\
\hline
\end{tabular}

Remaining 3 cases of laparotomy had uterine rent in 2 cases and the same was repaired, and 1 other patient had uterine and intestinal perforation requiring repair of the same (Table 8). There were 2 maternal deaths among the laparotomy cases. All cases of laparotomy had history of illegal attempt of surgical MTP by village quacks.

\section{The overall complications were}

30 cases had excessive hemorrhage and needed packed cell transfusion, 20 patients presented with generalized peritonitis, 3 women had DIVC and were managed with transfusion of blood products. 7 patients had deranged liver and kidney function. 3 woman had uterine perforation, 2 of them had bowel perforation and one girl had gangrene uterus and they all were managed with surgical exploration (Table 9). Total maternal deaths (due to all causes) were 48 . Deaths due to septic abortion constituted $6.25 \%(3 / 48)$ of the total deaths (Table 10). 
Table 9: Overall complications.

\begin{tabular}{|l|l|l|}
\hline Complications & Frequency & $\begin{array}{l}\text { Percentage } \\
(\%)\end{array}$ \\
\hline Hemorrhage & 30 & 68.1 \\
\hline Peritonitis & 20 & 45.4 \\
\hline $\begin{array}{l}\text { Disseminated } \\
\text { intravascular coagulation }\end{array}$ & 3 & 6.8 \\
\hline Deranged renal function & 7 & 15.9 \\
\hline Deranged liver function & 7 & 15.9 \\
\hline Uterine perforation & 3 & 6.8 \\
\hline Bowel perforation & 2 & 4.5 \\
\hline Gangrene uterus & 1 & 2.2 \\
\hline
\end{tabular}

Table 10: Total deaths due to unsafe abortions.

\begin{tabular}{|lll|}
\hline Mortality & $\begin{array}{l}\text { Number } \\
\text { of deaths }\end{array}$ & $\begin{array}{l}\text { Percentage } \\
(\%)\end{array}$ \\
\hline Total maternal deaths & 48 & 100 \\
\hline $\begin{array}{l}\text { Deaths due to septic } \\
\text { abortions }\end{array}$ & 3 & 6.25 \\
\hline Deaths due to other cause؛ & 45 & 93.75 \\
\hline
\end{tabular}

\section{DISCUSSION}

Unsafe abortions - Defined by WHO, as a procedure for the termination of unwanted pregnancy either by persons lacking the necessary skill/in an environment lacking the minimal medical standards or both. ${ }^{7}$

Septic abortion - is an infection of the placenta and fetus (products of conception) of a pre-viable pregnancy. Infection is centered in the placenta and there is risk of spreading to the uterus, causing pelvic infection or becoming systemic to cause sepsis and potential damage of distant vital organs. ${ }^{8}$ This includes not only septic criminal abortions, also miscarriages and elective abortions complicated by infection.

Our data confirms the high incidence of serious complications after illegal abortion, the morbidity extending further in terms of chronic PID, tubal damage, infertility, psychological trauma. At this point the Medical Termination of Pregnancy Amendment Bill 2014, has been proposed on increasing the availability of safe and legal abortion services for women in the country. ${ }^{9}$

Expanding the provider base-they conclude that abortion care can safely and effectively be provided by nurses and AYUSH practitioners. ${ }^{10,11}$

\section{Increasing the upper gestation limit for legal MTP's}

It is recommended to increase the gestational limit for seeking abortions on grounds of fetal abnormality beyond 20 weeks. It is also proposed to include increasing the gestation limit for safe abortion services for vulnerable categories of women expected to include survivors of rape and incest, single women (unmarried/ divorced/ widowed) and other vulnerable women (women with disabilities) to 24 weeks. ${ }^{12}$

\section{Increasing access to legal abortion services for women}

Reducing the condition of requirement of the opinion of two health care providers for second trimester pregnancies to one health care provider only, as this is seen as a hindrance in access to safe abortion services by women in situations where two providers are not available. The WHO 2012 guidance on "Safe abortion" also recommends reducing third party authorization. ${ }^{13}$ Extending the indication of contraception to include unmarried women.

\section{Increasing clarity of the MTP law}

It has been recommended to replace the term "registered medical practitioner" with "registered health care provider". This would cover the expanded provider base being suggested, by bringing in Nurses and ANMs as well as Ayurveda, Unani, Siddha and Homoeopath practitioners as legitimate providers of abortion service. ${ }^{14}$

Despite of the government's efforts at creating awareness amongst the people regarding the legalization of MTP services, many women from rural India still resort to quackery. Unsafe abortions can be prevented by.

Creating more awareness towards the usage of family welfare services. Effective contraception and avoiding unwanted pregnancies and safe abortions. Enforcement of strict laws against quackery. ${ }^{15}$ Prompt referral of these cases to and management at tertiary care center.

\section{CONCLUSION}

Septic abortion is totally preventable. Majority of uneducated rural women are not aware of MTP services. RCH services should effectively reach the underprivileged population like slum dwellers and migrants. The diverse system-related obstacles should be removed to provide quality health care for all. Public health facilities should be made more easily accessible.

Funding: No funding sources

Conflict of interest: None declared

Ethical approval: Not required

\section{REFERENCES}

1. Bashar M, Bhattacharya S, Singh A. Unsafe abortions in India: removing the Bottlenecks. Int $\mathbf{J}$ Med Public Health. 2018;8(1):42-4.

2. Ganatra B, Gerdts C, Rossier C, Johnson BR, Tunçalp Ö, Assifi A, et al. Global, regional, and sub regional classification of abortions by safety, 201014 estimates from a Bayesian hierarchical model. Lancet. 2017;390(10110):2372-81. 
3. Guttmacher institute. Fact sheet: Induced, global incidence and trends, 2016. Available at: https://www.guttmacher.org/fact-sheet/inducedabortion-worldwide. Accessed on March 2018.

4. Nour NM. An Introduction to maternal mortality. Reviews in Ob Gyn. 2008;1(2):77-81.

5. Schorge J, Schaffer J, Halvorson L, Hoffman B, Bradshaw K. Williams Gynecology. 1st Ed. McGraw-Hill Companies; 2008.

6. Hiralal K. DC Dutta's Textbook of Obstetrics. 7th Ed. Jaypee Brothers Medical Publishers; 2014.

7. Organització Mundial de la Salut, WHO, World Health Organization Staff, World Health Organization,.Safe Abortion: Technical and Policy Guidance for Health Systems, (World Health Organization; 2003:12.

8. David Eschenbach. Treating spontaneous and induced septic abortions. Obstet Gynecol. 2015;125(5):1042-8.

9. Government of India. Ministry of Health and Family Welfare Maternal Health Division. Available at: https://www.prsindia.org/uploads/media/draft/Draft $\% 20$ Medical $\% 20$ Termination\%20of\%20Pregnancy\% 20Amendment\%20Bill\%202014.pdf.

10. Shireen JJ, Shveta K, Shuchita M, Zavier TJ, Francis AJ, Acharya, R, et al. Feasibility of expanding the medication abortion provider base in India to include ayurvedic physicians and nurse. Int Perspect Sexual Reprod Health. 2012;38(3):133-42.

11. Jejeebhoy SJ, Kalyanwala S, Zavier AJ, Kumar R, Tank SJ, Jha AR. Can nurses perform manual vacuum aspiration (MVA) as safely and effectively as physicians? Evidence from India. Contraceptio. 2011;84(6):615-21.

12. Nimbalkar SM, Patel DS. The medical termination of pregnancy act: need to keep pace with technology. Indian J Med Ethics. 2018;096.

13. World Health Organization, Department of Reproductive Health and Research, Safe Abortion: Technical and Policy Guidance for Health Systems, (World Health Organization).2nd ed. 2012:68

14. Krishnan S. MTP Amendment Bill, 2014: towards re-imagining abortion care. Indian $\mathrm{J}$ Med Ethics. 2015;12(1):43-6.

15. Das V, Agarwal A, Mishra A, Deshpande P. Septic abortion. J Obstet Gynecol India. 2006;56(3):236-9.

Cite this article as: Mallaiyan S. Unsafe abortion: the silent scourge. Int J Reprod Contracept Obstet Gynecol 2019;8:3362-7. 